\title{
A IMPORTÂNCIA DOS PRINCÍPIOS DA BIOÉTICA NA FORMAÇÃO DO CIRURGIÃO DENTISTA CONTEMPORÂNEO
}

\author{
Songeli Menezes Freire', Urbino da Rocha Tunes² \\ Autora para correspondência: Songeli Menezes Freire - songeli.mf@gmail.com \\ 'Pós-Doutora em Biossegurança e em Bioética. Professora na Escola Bahiana de Medicina e Saúde Pública \\ e na Universidade Federal da Bahia. Salvador, Bahia, Brasil. \\ ${ }^{2}$ Doutor em Imunologia, Professor e Coordenador dos Cursos de graduação e pós-graduação (Mestrado) em Odontologia \\ da Escola Bahiana de Medicina e Saúde Pública. Salvador, Bahia, Brasil.
}

Na modernidade, os Cirurgiões Dentistas (CD), com todas as possibilidades do exercício de suas especialidades de trabalho, seja de gestor, responsável técnico, membro de grupo especialista ou multiprofissional, auditor, consultor, professor, preceptor ou pesquisador, de forma irrefutável, precisam seguir os códigos de ética e bioética para promoção de uma vida digna, pessoal, profissional e sócio-político-econômicoambiental sustentável. Um passo importante é reconhecer e proteger a dignidade humana, individual e coletiva, com princípios da responsabilidade e da precaução, da autonomia, não maleficência, beneficência, justiça e equidade.

Com o atual significado de Saúde, como não apenas a ausência de doença mas, também, como um estado de completo bemestar das dimensões físico, mental e social, segundo a OMS, pode-se complementar a condição auto-definida e a capacidade de se adaptar do indivíduo. Esta condição deve ser acompanhada pelo médico, na medicina personalizada, segundo publicação no livro "O normal e o patológico", em 1943, pelo médico francês Georges Canguilhem, resgatada recentemente'. Nesse editorial da
The Lancet, revista cientifica mundialmente reconhecida e valorizada, inclui-se também a dependência da interação saudável com o mundo inanimado em um sistema de troca de energia com a Terra. A nosso ver, a personalização da medicina pode ser complementária à saúde coletiva.

Com essas abordagens, resgatando que as alterações que alguns seres humanos, com sua atitude no âmbito pessoal ou profissional, de amplitude individual ou coletiva, provocam nos indivíduos, nos animais e no ecossistema, alterando a biodiversidade e a condição sócio-econômica-cultural, é possível concluir que, mesmo indiretamente, podem alterar e interferir sobre a dignidade humana e a sustentabilidade na vida em nosso meio e, consequentemente, pela globalização, no mundo e no nosso planeta. Ante a possibilidade das viagens e visitas à órbita e outros planetas, então, numa amplitude maior, essas ações podem ameaçar uma dimensão não só planetária, mas interplanetária.

O cirurgião dentista (CD) é um Profissional de Saúde (PS), considerado também como um agente da saúde, segundo o CFO em documento público de Código de Ética, 
estando habilitado, no Brasil, a planejar e executar procedimentos em prol do diagnóstico e tratamento, assim como da promoção da saúde, do paciente sob seus cuidados.

Os ensinamentos nos cursos de graduação e de pós-graduação autorizados e avaliados pelo MEC e CAPES, respectivamente, devem promover a habilitação nas áreas e especialidades do $C D$, no cumprimento de regras e conteúdos a serem trabalhados para atender à demanda atual e futura do país. Assim, devem contemplar aprofundamento de temas para prepará-los para a percepção, antecipação, minimização e solução de conflitos. Incluindo considerar e cuidar das necessidades coletivas e individuais, e pessoais de autoestima e de auto-aceitação. $O C D$ precisa estar preparado, deste modo, para a demanda de cuidados essenciais básicos (primários) e também para a melhoria do bem-estar, fundamental para a saúde no contexto atual, com segurança para com os pacientes e trabalhadores sob sua responsabilidade. Epidemiologicamente, por exemplo, esses indivíduos podem estar submetidos a fatores de risco para doenças sistêmicas crônicas, como diabetes, doenças cardiovasculares e osteoporose, bem como a processos falcêmicos, como se observa na população da Bahia. Considerações como estas convergem ao reconhecimento da necessidade do $C D$ nas Unidades de Terapia Intensiva e de clínicas de tratamento de doentes crônicos, o que produz implicações fundamentais para a compreensão da importância da saúde bucal na saúde sistêmica, e a real necessidade da inclusão de $C D$ nas equipes multiprofissionais dos setores de Gestão e de Serviços de Atendimento à Saúde.

Diante do exposto, fica mais evidente a importância da educação e formação do profissional ético capaz, mais responsável e sensível à bioética. A ética pode ser referida de forma simples como fazer o bem pelo bem e de se chegar, e favorecer ao outro, à felicidade e à plenitude. E é inegável a relação de princípios da moral e da ética com os aspectos da fragilidade do sistema de saúde pública no Brasil e em vários países em desenvolvimento.

Aldo Leopold, filósofo e ambientalista na década de 1930, referenciado como filósofo da terra, porque refletiu sobre a importância da manutenção da saúde e da estabilidade da terra; Albert Schweitzer, filósofo, médico e Prêmio Nobel da paz de 1952, trabalhou toda a sua vida com base na ética, na saúde e no amor ao próximo bem como formou grupo de profissionais sensíveis a ajudar as pessoas sofridas de países pobres e devastados pela guerra, da África, e pode ser um exemplo de resgate e promoção à busca e reforço à dignidade das pessoas.

No final da década de 1920, Fritz Jahr cunhou na Alemanha a palavra bioética como "a emergência de obrigações éticas não apenas com o homem, mas com todos os seres vivos", e trouxe o Imperativo Bioético: "respeita cada ser vivo, em princípio, como uma finalidade em si e trata-o como tal na medida do possível". Esta nova palavra ficou isolada, suposta e, provavelmente, pela dificuldade de divulgação cientifica da época, bem antes da tão difundida e reconhecida definição por Van Ressler Potter, na década de 1970. A bioética vem sendo constantemente redefinida, por convergência, desde as ideias do princípio da responsabilidade de Hans Jonas, publicado entre 1979 e 1984, tão sabiamente relacionado com as ações das pessoas, seus impactos e consequências futuras.

A Bioética torna-se, então, fundamental nas fases iniciais de educação do indivíduo cidadão e se deve fomentar a discussão sobre Bioética, nas áreas da saúde, para o necessário empoderamento das pessoas, enraizamento da responsabilidade dos educadores e das instituições, para o direito ao exercício da autonomia, e a uma vida plena e mais justa $^{2,3}$. Finalmente, aprofundamos e estendemos a partir de todas as definições, uma bioética que serve de guia nas ações e reflexões sobre o efeito e as consequências do avanço cientifico, biomédico e tecnológico, e do próprio conhecimento, sobre a vida dos indivíduos e coletividade, dos seres, dos ambientes, no planeta e espaços interplanetários.

Dentro da academia e dos centros de estudo, diferentes autores filósofos e bioeticistas fazem reflexões, classificações e abrangências da Bioética. Neste contexto soma-se uma legislação rígida atualmente quanto ao uso de animais para ensino e pesquisa, assim como nas pesquisas com seres humanos. 
A ética resulta da dedicação de diversos filósofos, pensadores e ambientalistas, quanto ao futuro da vida terrestre e da humanidade. São exemplos, classificações, como a bioética das reflexões, utilitarista, intervencionista, do cotidiano ou de fronteira e, mais tarde, a complexa de Goldim. Outro aspecto importante é o de lidar com a integridade acadêmica e científica e, a eticidade, que deve ser além do pessoal, no caso, sobre o pensamento crítico, a investigação que deve ser sustentada com a revisão do novo conhecimento, tendo como base a evidência científica e a consciência sobre os seus efeitos.

Ressalta-se, ainda, no papel do $C D$ técnico, professor, representante político, profissional pesquisador, jornalista, a responsabilidade do alerta sobre a pós-verdade, que diz respeito a circunstâncias nas quais fatos objetivos têm menos importância do que crenças pessoais ou, ainda, segundo o dicionário Oxford, a qualidade de se parecer ou se sentir como verdadeira, mesmo que não seja necessariamente verdadeira. Devem ser incentivadas ações e reflexões de integridade acadêmica e científica nos modelos educativos e científicos, assim como a reflexão sobre fatores interferentes do conhecimento e no empoderamento ou fragilização da qualidade da saúde e de vida; da situação, estrutural e intelectual, a nível públicoprivado, individual, empresarial e nacional; e, mais uma vez, devido à tecnologia da informação e da divulgação, em todo o mundo. Esses pressupostos norteiam a formação para o exercício de atividades de gestão, responsabilidade técnica, membro de equipe especializada / multiprofissional, na docência e/ou pesquisa, com a devida importância da autonomia e informação na relação dos CD's com pessoas a quem assiste / colaboradores / pacientes / clientes / consumidores e dos participantes da pesquisa, cuidando dos termos de responsabilidade, de ciência e de consentimento/assentimento.

De tudo isso, fica claro que os CD's devem cumprir recomendações e mecanismos de fiscalização e instrumentos legais envolvidos na sua ação como Profissional da Saúde. Devem sentir a responsabilidade sobre todo processo e/ou produtos consequentes de suas ações, incluindo reflexões sobre a saúde como um todo e sobre a geração e destino de resíduos, e do uso de água e de energia.
Os CD's de boa formação devem cumprir, assim, suas funções com responsabilidade, sensibilidade $e$ consciência, contribuindo verdadeiramente para um mundo melhor, mais justo e sustentável.

\section{REFERÊNCIAS}

1. The Lancet. What is health? The ability to adapt. The Lancet. 2009;373:781

2. Azevêdo EES. Ensino de Bioética: um desafio transdisciplinar. Interface - Comunicação, Saúde, Educação. 1998;2(2):1 27-138.

3. Casado M. Sobre la dignidad y los principios. Artículo 23. Educación, formación e información en materia de bioética. Pag. 51 1-521 En SOBRE LA DIGNIDAD Y LOS PRINCIPIOS. Análisis de la Declaración Universal sobre Bioética y Derechos Humanos UNESCO. Coordinadora: MARÍA CASADO. ISBN: 978-84-470-3261-7 Ed. Civitas, 2009, 600 pp., ISBN 978-84-4703-261-7. Version digital disponible en el site del OBD, solicitud libro http://www.bioeticayderecho. ub.edu. 2009 